\title{
The control of paramyxovirus genome hexamer length and mRNA editing
}

\author{
YUSUKE MATSUMOTO, ${ }^{1}$ KEISUKE OHTA, ${ }^{1}$ DANIEL KOLAKOFSKY, ${ }^{2}$ and MACHIKO NISHIO ${ }^{1}$ \\ ${ }^{1}$ Department of Microbiology, School of Medicine, Wakayama Medical University, Wakayama 641-8509, Japan \\ ${ }^{2}$ Department of Microbiology and Molecular Medicine, University of Geneva School of Medicine, 1211 Geneva, Switzerland
}

\begin{abstract}
The unusual ability of a human parainfluenza virus type 2 (hPIV2) nucleoprotein point mutation (NP ${ }^{\mathrm{Q} 202 \mathrm{~A}}$ ) to strongly enhance minigenome replication was found to depend on the absence of a functional, internal element of the bipartite replication promoter (CRII). This point mutation allows relatively robust CRII-minus minigenome replication in a CRII-independent manner, under conditions in which $\mathrm{NP}^{\mathrm{wt}}$ is essentially inactive. The nature of the amino acid at position 202 apparently controls whether viral RNA-dependent RNA polymerase (vRdRp) can, or cannot, initiate RNA synthesis in a CRII-independent manner. By repressing genome synthesis when vRdRp cannot correctly interact with CRII, gln ${ }^{202}$ of $\mathrm{N}$, the only residue of the RNA-binding groove that contacts a nucleotide base in the N-RNA, acts as a gatekeeper for wild-type (CRII-dependent) RNA synthesis. This ensures that only hexamer-length genomes are replicated, and that the critical hexamer phase of the cis-acting mRNA editing sequence is maintained.
\end{abstract}

Keywords: paramyxoviruses; human parainfluenza virus type 2; nucleoprotein; bipartite replication promoters

\section{INTRODUCTION}

Each nucleoprotein (N or NP) protomer of paramyxovirus nucleocapsids (N/NP-RNAs) is associated with precisely 6 nucleotides (nt), and overall genome nucleotide length must be precisely a multiple of 6 (Egelman et al. 1989; Calain and Roux 1993; Kolakofsky et al. 1998, 2005). Paramyxovirus genome replication is governed by this "rule of six," which is thought to act during promoter recognition and the initiation of RNA synthesis from the genome $3^{\prime}$ end. Because hexamer length genomes have a strong replicative advantage, this rule imposes a hexamer phase on the entire RNA genome. The structural basis for this rule, deduced from the cryo-EM reconstruction of the measles virus (MeV) N-RNA (Gutsche et al. 2015), is that, of the 6 nucleotides associated with each $\mathrm{N}$ protomer, three contiguous bases are stacked and pointed toward the solvent (or "out"; i.e., hexamer positions 5 and 6 , and position 1 of the next $\mathrm{N}$ protomer) (Fig. 1). The other three bases are stacked and point toward the protein core (hexamer positions 2, 3, and 4; or "in") (Fig. 1). This alternating arrangement of three-base stacks (positions $5,6,1^{\text {out }} 2,3,4^{\text {in }}$ $5,6,1^{\text {out }} 2,3,4^{\text {in }}$ ) is imposed on the bound RNA by $\mathrm{N}$ protein structure, and is found throughout the N-RNAs, except presumably at their very ends (Gutsche et al. 2015).

Because paramyxovirus genomes are precisely of hexamer length, each nucleotide within cis-acting sequences also has

Corresponding author: mnishio@wakayama-med.ac.jp

Article is online at http://www.rnajournal.org/cgi/doi/10.1261/rna. 065243.117. a precise hexamer position within each $\mathrm{N}$ protomer; and these positions are conserved within each genera. This is particularly important for $3^{\prime}$ end promoters that are bipartite in nature, being composed (at a minimum) of the first $12 \mathrm{nt}$ at very $3^{\prime}$ genome end (critical region I or CRI). The second component (CRII) is found in the $5^{\prime}$ UTR of the first (N) gene and the $3^{\prime}$ UTR of the last (L) gene, and is simply cytosine at hexamer position $1\left(\right.$ hex $\left.^{1}\right)$ of hexamers 14,15 , and 16 (from the $3^{\prime}$ end) for Sendai virus (SeV), human parainfluenza virus type 3 (hPIV3) (respiroviruses), and MeV (a morbillivirus) (Pelet et al. 1996; Tapparel et al. 1998; Walpita 2004). Rubulavirus PIV5 CRII is also very simple, GC at hex ${ }^{5}$ and hex $^{6}$ of hexamers 13, 14, and 15 (Fig. 1; Murphy et al. 1998; Murphy and Parks 1999). CRI and CRII are thus found on the same vertical face of the N-RNA helix, such that viral RNA-dependent RNA polymerase (vRdRp) presumably can simultaneously contact both elements of the promoter. Tellingly, CRI/CRII nt spacing must be exact, as the displacement of CRII tripartite repeat by even $1 \mathrm{nt}$ position strongly reduces genome replication (Pelet et al. 1996; Murphy et al. 1998).

The RNA in resting nonsegmented negative-strand RNA virus (nsNSV) N-RNAs is tightly bound to the $\mathrm{N}$ protomer chain predominantly via its ribose- $\mathrm{PO}_{4}$ backbone, in a deep,

(c) 2018 Matsumoto et al. This article is distributed exclusively by the RNA Society for the first 12 months after the full-issue publication date (see http:// rnajournal.cshlp.org/site/misc/terms.xhtml). After 12 months, it is available under a Creative Commons License (Attribution-NonCommercial 4.0 International), as described at http://creativecommons.org/licenses/by-nc/4.0/. 
Respirovirus / Morbillivirus

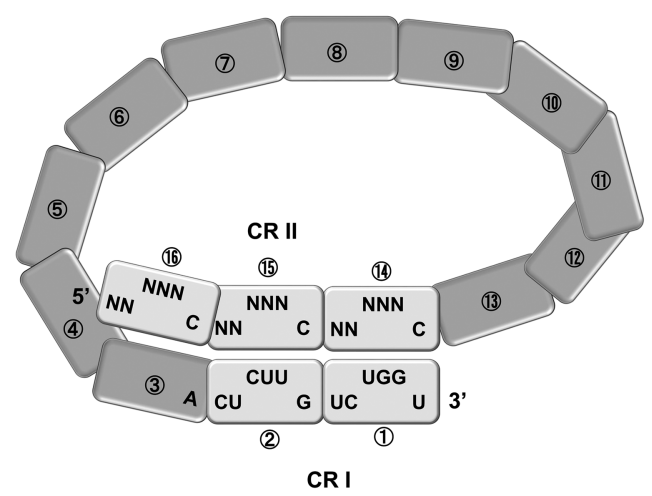

$\therefore$

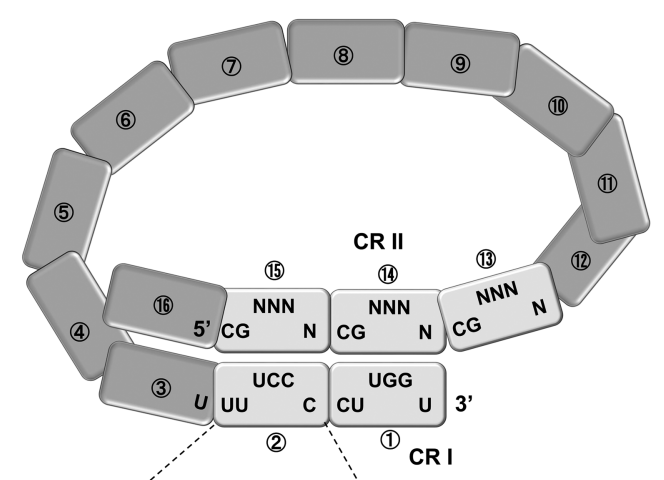

\section{$\underline{\text { Rubulavirus }}$}

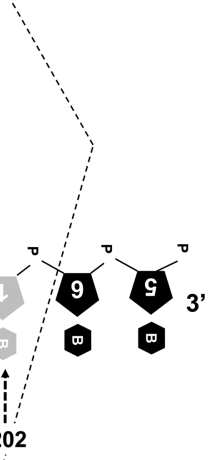

FIGURE 1. Paramyxovirus bipartite genome promoters. Schematic diagram of NP-RNA $3^{\prime}$ end and bipartite promoters of SeV (as a representative Respirovirus) and hPIV2 (as a representative Rubulavirus). The NP subunits (and the hexamer positions within each subunit) are numbered from the genome $3^{\prime}$ end. Critical regions CRI and CRII indicate the conserved elements of the bipartite promoters. The interactions of the various RNA-binding residues of hPIV2/5 NP with the ribonucleotides at each hexamer position, numbered in their pentagonal ribose rings, are shown below. The amino acids found in each of the two RNA-binding pockets are indicated.

positively charged groove between the $\mathrm{N}$-ter and C-ter domains of the nucleoprotein (Ruigrok et al. 2011). The X-ray crystal structure of PIV5 NP-RNA rings shows the same alternate orientation of these three-base stacks, and the RNA is bound to the PIV5 nucleoprotein in a similar fashion as the other nsNSV N-RNAs (Albertini et al. 2006; Green et al. 2006; Luo et al. 2007; Tawar et al. 2009; Alayyoubi et al. 2015). Ten residues of PIV5 NP make contact with the bound RNA; nine with the ribose- $\mathrm{PO}_{4}$ backbone, and one, Q202, with the base at hex ${ }^{1}$ (Alayyoubi et al. 2015). hPIV2 and PIV5 are closely related rubulaviruses, and their NP protein sequences, including these 10 residues, are highly conserved (Matsumoto et al. 2017). In studying the effect of individually mutating each of these residues to alanine on minigenome reporter gene expression, an interesting pattern emerged (Matsumoto et al. 2017). Mutation of those amino acids that contacted the ribose- $\mathrm{PO}_{4}$ backbone of nucleotides whose bases pointed "in" were mostly neutral. Mutation of those residues that contacted the RNA backbone of nucleotides whose bases pointed out clearly inhibited reporter gene expression. However, mutation of Q202, in contrast, unexpectedly led to strongly enhanced reporter gene expression $(>30$-fold relative to $\left.\mathrm{NP}^{\mathrm{wt}}\right)$. This report examines the nature of the $\mathrm{NP}^{\mathrm{Q} 202 \mathrm{~A}}$ mutation, and provides evidence that the nature of the amino acid at this position controls whether vRdRp can, or cannot, initiate RNA synthesis in a CRII-independent manner. These experiments shed light on the mechanism by which CRII controls vRdRp initiation of RNA synthesis, and why the requirement for genome hexamer length, bipartite replication promoters and $\mathrm{P}$ gene mRNA editing, which are unique to paramyxoviruses among nsNSV, are linked.

\section{RESULTS}

\section{Enhanced minigenome replication in the presence of $\mathrm{NP}^{\mathrm{Q} 202 \mathrm{~A}}$ is due to the absence of a CRII element}

NP participates in RNA synthesis in several ways. NP protomers form a chain that encapsidates the entire genome RNA, $6 \mathrm{nt}$ at a time, forming helical NP-RNA nucleocapsids. Individual groups of protomers also need to be transiently displaced from the template RNA during RNA synthesis, so the template can be transcribed within the RdRp synthesis chamber. Moreover, for genome and antigenome (G/AG) synthesis, vRdRp's processivity on the template is likely coupled to the concurrent assembly of the nascent replicate RNA with NP, as nascent nucleocapsids are fully assembled (Gubbay et al. 2001). 
We previously reported that mutation of $\mathrm{NP}^{\mathrm{Q} 202}$ to ala $\left(\mathrm{NP}^{\mathrm{Q} 202 \mathrm{~A}}\right)$ led to strongly enhanced minigenome replication and reporter gene expression in a cell culture system (Matsumoto et al. 2017). The minigenome used in this study, however, was subsequently found to be missing the region containing the CRII element of the antigenome promoter (AG/CRII $\left.{ }^{\text {minus }}\right)$. When minigenomes containing both wt promoters $\left(\mathrm{AG}^{\mathrm{wt}}\right)$ were reexamined, $\mathrm{NP} \mathrm{N}^{\mathrm{wt}}$ again very poorly promoted Rluc expression from Rluc-AG/CRII ${ }^{\text {minus }}$, whereas $\mathrm{NP}^{\mathrm{Q} 202 \mathrm{~A}}$ showed robust activity (black bars, Fig. 2). However, when the minigenomes contained both wt replication promoters (Rluc- $\mathrm{AG}^{\mathrm{wt}}$ ), $\mathrm{NP}^{\mathrm{Q} 202 \mathrm{~A}}$ had no obvious phenotype; $\mathrm{NP}^{\mathrm{wt}}$ performed as well as $\mathrm{NP}^{\mathrm{Q} 202 \mathrm{~A}}$ in Rluc expression (Fig. 2). Tellingly, in both cases, Rluc expression levels were almost twice that of the AG/CRII ${ }^{\text {minus }} / \mathrm{NP}^{\mathrm{Q} 202 \mathrm{~A}}$ combination. The unusual phenotype of $\mathrm{NP}^{\mathrm{Q} 202 \mathrm{~A}}$ is thus "synthetic," as it depends on the absence of a CRII element. The more important finding was that $\mathrm{NP}^{\mathrm{Q} 202 \mathrm{~A}}$, in contrast to $\mathrm{NP}^{\mathrm{wt}}$, promotes Rluc expression independent of AG/CRII. The most straightforward interpretation of these results is that whereas $\mathrm{NP}^{\mathrm{wt}}$ supported minigenome replication requires both elements of the bipartite promoter, $\mathrm{NP}^{\mathrm{Q} 202 \mathrm{~A}}$ has acquired the ability to support minigenome replication in the absence of AG/CRII.

This result is reminiscent of the analogous phenotype of $\mathrm{NP}^{\mathrm{Q} 202 \mathrm{~A}}$ when the CRII element of the genomic promoter is inactivated $\left(\mathrm{G} / \mathrm{CRII}{ }^{\mathrm{minus}}\right)$ in the background of $\mathrm{AG} /$
CRII ${ }^{\text {minus }}$, i.e., when both CRII elements are absent. G/ CRII $^{\text {minus }}$ was inactivated not by its deletion (like that of AG/CRII ${ }^{\text {minus }}$ ), but by displacing its tripartite repeats from their precise locations, either via successive $6 \mathrm{nt}$ deletions, or 1 to $5 \mathrm{nt}$ deletions, both within the leader region (Matsumoto et al. 2017). As found previously, these AG/ $\mathrm{CRII}^{\text {minus }} / \mathrm{G} / \mathrm{CRII}{ }^{\text {minus }}$ minigenomes displayed clear Rluc activity only when driven by $\mathrm{NP}^{\mathrm{Q} 202 \mathrm{~A}}$ (up to $60 \%$ of that of AG/ $\mathrm{CRII}^{\text {minus }}$ that lacks only one CRII element). Thus, $\mathrm{NP}^{\mathrm{Q} 202 \mathrm{~A}}$ similarly allows relatively robust RNA synthesis from the "mutant" G/CRII minus promoter under conditions where $\mathrm{NP}^{\mathrm{wt}}$ is again essentially inactive. $\mathrm{NP}^{\mathrm{Q} 202 \mathrm{~A}}$ has thus similarly acquired the ability to support minigenome replication independent of CRII of the genomic promoter. This property of $\mathrm{NP}^{\mathrm{Q} 202 \mathrm{~A}}$, of supporting RNA synthesis from CRII ${ }^{\text {minus }}$ promoters under conditions where $\mathrm{NP}^{\mathrm{wt}}$ is inactive, can more clearly be seen with minigenomes that contain the same AG/CRII ${ }^{\text {minus }}$ (trailer) promoter on both genomes and antigenomes (Fig. 3). As the Rluc genes of these copyback-like minigenomes lack a gene-start signal, they are essentially templates only for genome replication.

\section{$\mathrm{NP}^{\mathrm{Q} 202}$ and the initiation of genome replication}

Minigenomes that lack a CRII element are essentially inactive when $\mathrm{NP}^{\mathrm{wt}}$ supports their replication (Pelet et al. 1996).

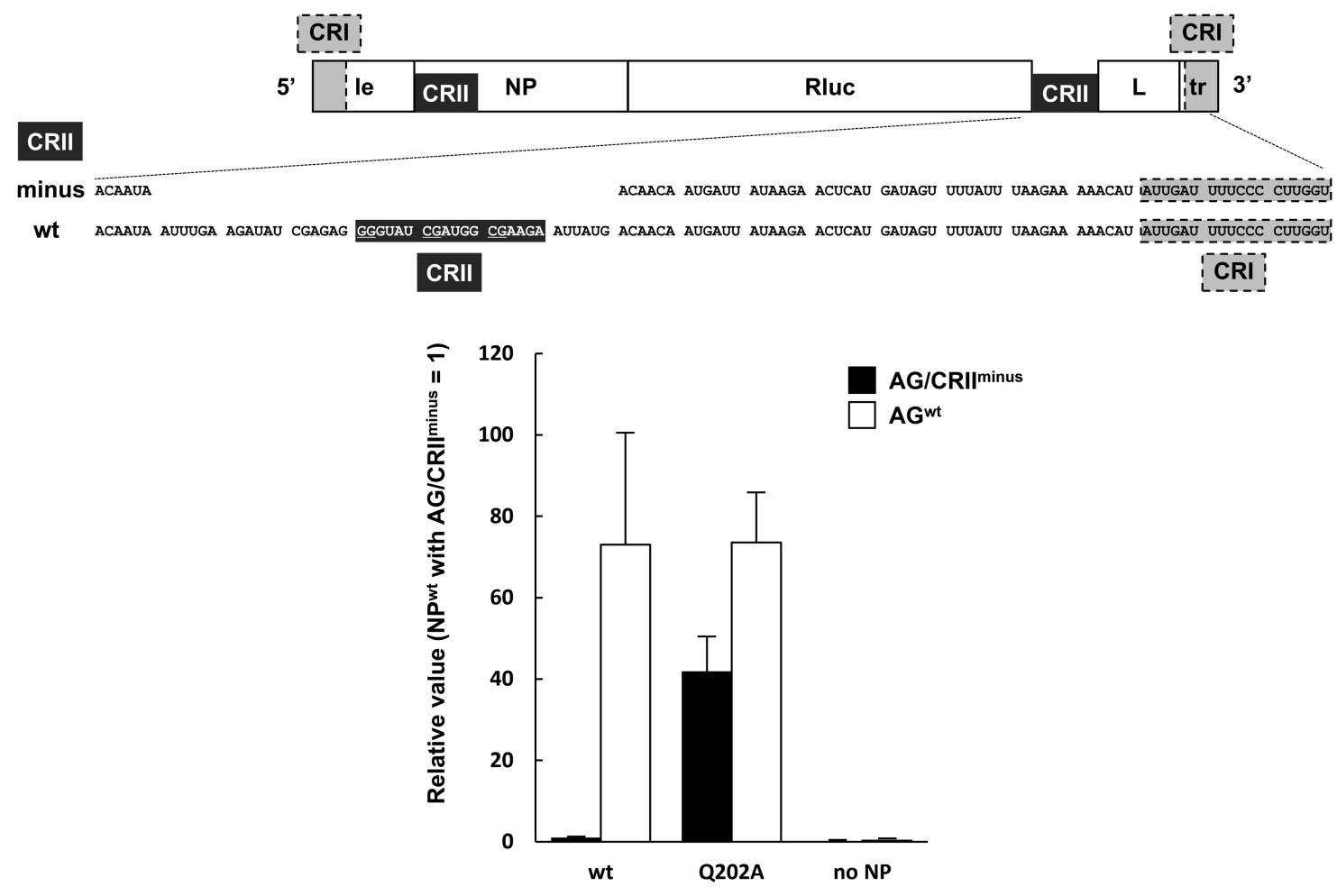

FIGURE 2. Luciferase expressions during $\mathrm{NP}^{\mathrm{wt}}$ or $\mathrm{NP}^{\mathrm{Q} 202 \mathrm{~A}}$ supported replication of hPIV2 minigenomes with or without the internal element of the antigenomic promoter (AG ${ }^{\mathrm{CRII}}$ ). hPIV2 minigenomes with or without CRII were subjected to a minireplicon assay supported by NP ${ }^{\mathrm{wt}}$ or NP2202A . The Rluc expressions from minigenomes were normalized to an internal control Fluc expression, and relative values are shown (NP ${ }^{\mathrm{wt}}$ with CRII-minus $=1$ ). Data represent means and standard deviations from three separate experiments. 

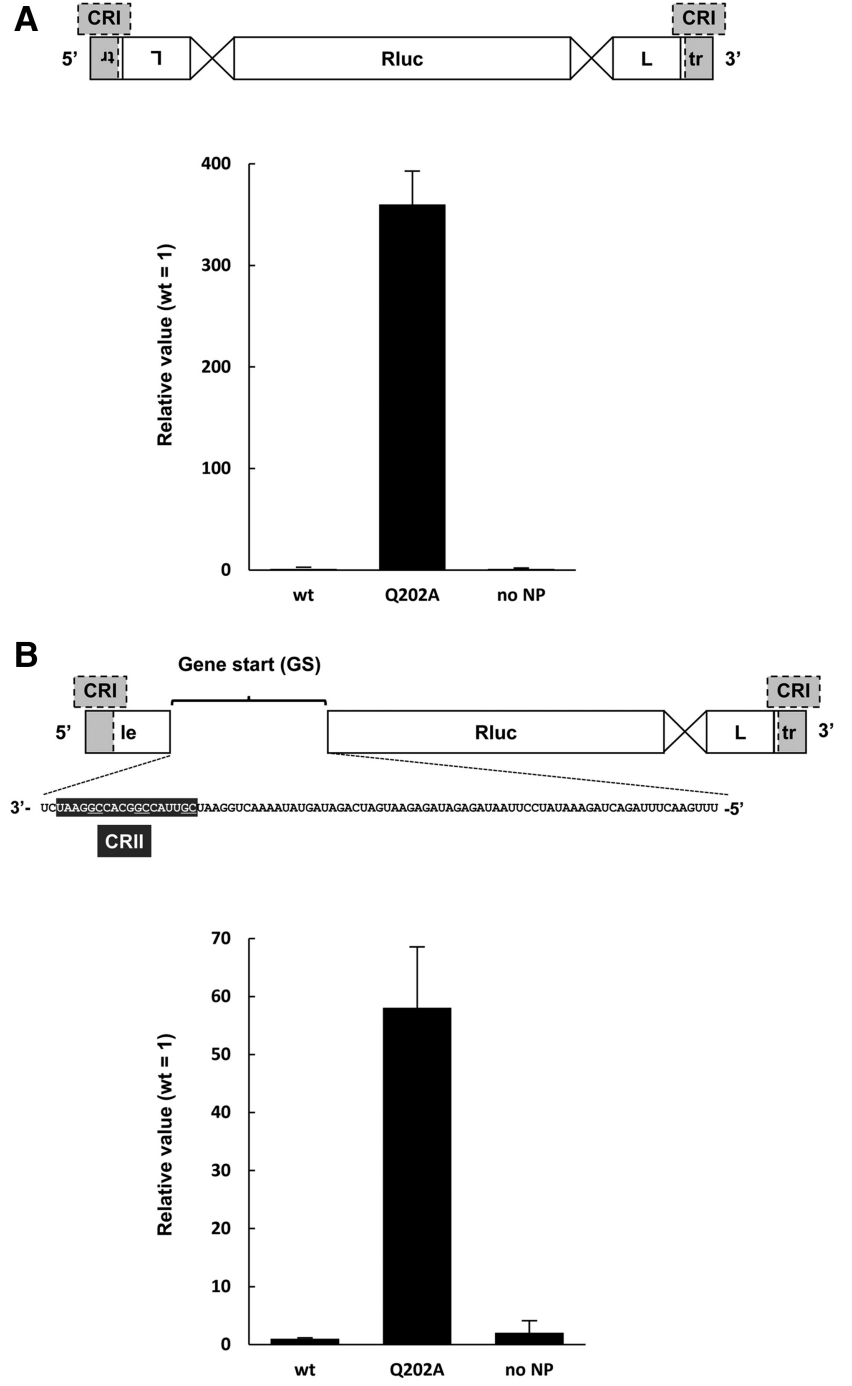

FIGURE 3. Replication of $\mathrm{NP}^{\mathrm{wt}}$ or $\mathrm{NP}^{\mathrm{Q} 202 \mathrm{~A}}$ supported minigenomes lacking both CRII elements. Antigenome replication levels of trailertrailer copyback-like minigenome $(A)$, and a minigenome whose gene start signal is deleted $(B)$ are shown. NP-encapsidated NP-RNAs were isolated by immunoprecipitation after replication. The relative amounts of antigenome were measured by qRT-PCR and shown as relative values $(\mathrm{NP} w \mathrm{wt}=1)$. Data represent means and standard deviations from three separate experiments.

Mutation of $\mathrm{NP}^{\mathrm{Q} 202}$ to ala, however, allows relatively robust Rluc expression from CRII ${ }^{\text {minus }}$ minigenomes. Thus, unlike $\mathrm{NP}^{\mathrm{wt}}$-supported minigenome replication where CRII is important for vRdRp to initiate at CRI, vRdRp in $\mathrm{NP}^{\mathrm{Q} 202 \mathrm{~A}}$-supported minigenome replication can apparently initiate at CRI in a CRII-independent fashion. As gln/ala ${ }^{202}$ may be interacting with every base at hex ${ }^{1}$ of their respective NP-RNAs, these different interactions might well affect NP-RNA structure. The CRI cis-acting sequences of resting $\mathrm{NP}^{\mathrm{Q} 202 \mathrm{~A}}-\mathrm{RNAs}$ may then be more accessible to vRdRp than those in NP ${ }^{\mathrm{wt}}$ RNAs, and vRdRp may no longer be as dependent on CRII interaction to facilitate the initiation of RNA synthesis.
RNA synthesis initiates at the $3^{\prime}$ terminal uridine that is unique not only because of its free $3^{\prime} \mathrm{OH}$ group; it is presumably also the only base at hex ${ }^{1}$ that is not part of a three-base stack. For RNA synthesis to initiate here, two or three $3^{\prime}$ terminal NP protomers need to be separated from the template RNA, exposing 12-18 nt of naked RNA whose $3^{\prime}$ end needs to end up at the active site within vRdRp. In NP ${ }^{\mathrm{wt}}$-RNAs, the presence of $\operatorname{gln}^{202}$ somehow restricts initiation at CRI when vRdRp cannot also correctly interact with CRII. It is the apparent absence of $\operatorname{gln}^{202}$ that relieves this restriction in CRII ${ }^{\text {minus }}$ minigenomes, as the replacement of gln ${ }^{202}$ with several amino acids other than ala recapitulates the CRII-independent phenotype (Matsumoto et al. 2017). In this view, gln ${ }^{202}$ acts negatively on initiation, and this inhibition is then neutralized by vRdRp/CRII interaction under wild-type conditions.

Carrying out CRII ${ }^{\text {minus }}$ minigenome replication when both $\mathrm{NP}^{\mathrm{wt}}$ and $\mathrm{NP}^{\mathrm{Q} 202 \mathrm{~A}}$ are present may be informative in examining this hypothesis. As $\mathrm{NP}^{\mathrm{wt}}$ - and $\mathrm{NP}^{\mathrm{Q} 202 \mathrm{~A}}$-supported replication levels of wt minigenomes are very similar (open bars, Fig. 2), there is apparently little preference for either NP occupying each hexamer during NP-RNA assembly. The probability of each NP binding each hexamer will then simply depend on their relative concentrations. In this mixed NP system, we expect that the $3^{\prime}$ terminal uridine of the NPRNA must not be interacting with $\operatorname{gln}^{202}$, as this interaction prevents the initiation of RNA synthesis in a CRII-independent manner. If this interaction, and/or similar interactions, determines whether vRdRp will initiate at CRI, then relative replication levels will vary relative to their NP concentrations in a manner that reflects this. For example, if this interaction with the $3^{\prime}$ terminal uridine alone predominantly determines activity, when $\mathrm{NP}^{\mathrm{Q} 202 \mathrm{~A}}$ is $1 / 4$ of the total, replication levels will simply be $25 \%$ of that when only $\mathrm{NP}^{\mathrm{Q} 202 \mathrm{~A}}$ is present. If two bases at hex ${ }^{1}$ of two hexamers must be excluded from interaction with $\operatorname{gln}^{202}$, relative replication levels will be $(1 / 4)^{2}$ or $6 \%$ of that when only $\mathrm{NP}^{\mathrm{Q} 202 \mathrm{~A}}$ is present. Similarly, if three bases at hex ${ }^{1}$ of three hexamers must be excluded, relative replication levels will be $(1 / 4)^{3}$ (or $1.5 \%$ ) of that when only $\mathrm{NP}^{\mathrm{Q} 202 \mathrm{~A}}$ is present. The correspondence between the results of Figure 4 and these theoretical probabilities suggest that, on average, two bases at hex ${ }^{1}$ of two hexamers must be excluded from interacting with gln ${ }^{202}$ for vRdRp to initiate, according to this view. We appreciate that there are other possible interpretations of these results. Nevertheless, the finding that CRII ${ }^{\text {minus }}$ minigenome replication is hypersensitive to the presence of $\mathrm{NP}^{\mathrm{wt}} / \mathrm{gln}^{202}$ is consistent with this residue acting in a complex negative manner. The ease with which the two $3^{\prime}$ terminal NP protomers can be separated from the genome RNA during the initiation of RNA synthesis could then determine whether vRdRp can initiate in a CRII-independent manner.

\section{DISCUSSION}

NSV RdRps have a conserved architecture, with their synthesis chambers buried in the protein core that communicates 


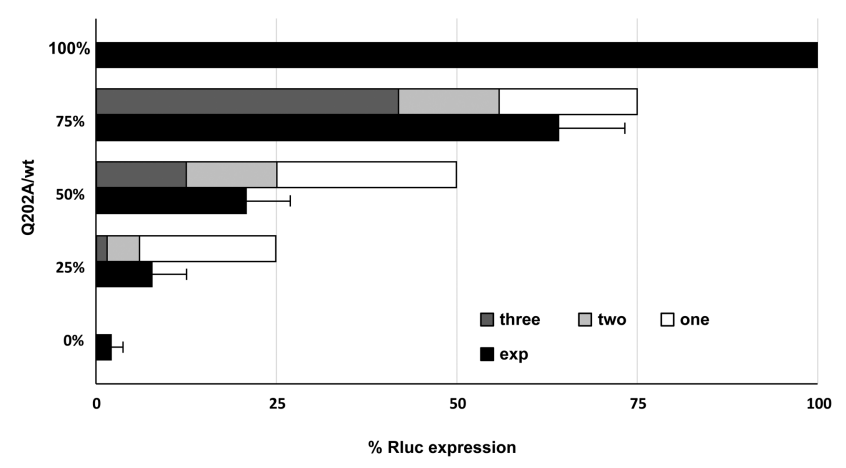

FIGURE 4. CRII $^{\text {minus }}$ minigenome replication with mixtures of $\mathrm{NP}^{\mathrm{wt}}$ and $\mathrm{NP}^{\mathrm{Q} 202 \mathrm{~A}}$. Various mixtures of $\mathrm{NP}^{\mathrm{Q} 202 \mathrm{~A}}$ and $\mathrm{NP}^{\mathrm{wt}}$ expressing plasmids, as indicated on the left, were used to support AG/CRII ${ }^{\text {minus }}$ minigenome replication, and the various Rluc expression levels were determined. The black bars show the \% Rluc expression at each $\mathrm{NP}^{\mathrm{Q} 202 \mathrm{~A}}$ vs NP $\mathrm{NP}^{\mathrm{wt}}$ mixture relative to that of $100 \%$ Q202A. Data represent means and standard deviations from three separate experiments. The tricolored bar above each all-black data bar shows the expected relative Rluc values if one, two, or three gln202/hex 1 interactions need to be excluded to permit RNA synthesis (see text).

with the outside via four channels (Reguera et al. 2016). That of vesicular stomatitis virus (VSV), the only nsNSV RdRp for which a high resolution structure is available (Liang et al. 2015), is similar and serves as a stand-in for paramyxovirus RdRp. Initiation of genome RNA synthesis requires the displacement of two or three $3^{\prime}$ terminal Ns of the N-RNA, exposing 12-18 nt of the genome RNA. The $3^{\prime}$ end of this genome RNA must then find its way to the active site within vRdRp; the entire pathway of the template through VSV RdRp would accommodate roughly 25 nt (Liang et al. 2015). The manner in which vRdRp carries out this complex task is unknown. We do not know whether RNA sequence affects how $\mathrm{N}$ is transiently separated from the template RNA during the initiation of RNA synthesis. However, a fusion construct of $\mathrm{MeV} \mathrm{P}$ and $\mathrm{N}$ proteins can act to assemble nucleocapsid-like particles in vitro, and this assembly was strongly sequence-dependent (Milles et al. 2016). The displacement of the $3^{\prime}$ proximal $\mathrm{N}$ protomers from the template RNA during the initiation of RNA synthesis might similarly be sequence-sensitive, and the hPIV2 polypyrimidine run from $3^{\prime} \mathrm{U}_{4}$ to $\mathrm{U}_{13}$ (Fig. 1) might play a role in this process.

The nucleotide bases of MeV and PIV5 N/NP-RNA structures are simply modeled as uracil, so the precise manner in which $\mathrm{N}$ can discriminate the various nucleotide bases is unclear. Nevertheless, there are significant interactions between nucleotide base moieties and the N/NP protein surface in both the MeV and PIV5 structures (Alayyoubi et al. 2015; Milles et al. 2016), including base-specific hydrogen bonding between Q202 and the uracil modeled at hex ${ }^{1}$. Gln ${ }^{202}$ could inhibit the initiation of RNA synthesis by strongly interacting with the cis-acting sequences of CRI, including the $3^{\prime}$ uridine at hex ${ }^{1}$, making the transient displacement of NP from the $3^{\prime}$ terminal hexanucleotides more difficult. This inhibition would presumably be relieved by $\mathrm{vRdRp}$ interacting with
CRII, which could, for example, stabilize its interaction with the promoter and give vRdRp more time to get the job done. Conformational changes in vRdRp due to this interaction may also play a role (see below).

We have known for some time that vRdRp does not initiate RNA synthesis at the genome $3^{\prime}$ end when the hexamer phase of CRII is displaced from its conserved position, but not how this selective initiation operates. These studies with $\mathrm{NP}^{\mathrm{Q} 202 \mathrm{~A}}$ provide a clue. The requirement for genome hexamer length, bipartite replication promoters, and $\mathrm{P}$ gene mRNA editing are unique to paramyxoviruses. These three properties are presumably linked because the hexamer phase of the cis-acting mRNA editing sequence, as well as the sequence itself, controls mRNA editing and needs to be conserved (Iseni et al. 2002; Kolakofsky 2016). Hexamer phasing of cis-acting sequences, of course, requires hexamer length genomes, and this apparently requires a bipartite promoter. These bipartite promoters ensure that genomes with nonhexamer length insertions or deletions are poorly replicated, because such changes in genome length automatically alter the hexamer phase of the CRII tripartite repeat. Hexamer genome length and bipartite promoters are thus essential to maintain genome sequence phasing. Paramyxovirus bipartite promoters would operate by having a negative element acting at CRI $\left(\mathrm{gln}^{202}\right)$ that needs to be neutralized by a positive element acting at CRII (vRdRp/tripartite repeat interaction), and this positive element is known to be sensitive to hexamer phase. The critical hexamer phase of the mRNA editing sequence, $2486 \mathrm{nt}$ removed from the genome $3^{\prime}$ end, is thus conserved by that of the tripartite repeat at CRII.

The need to conserve the hexamer phase of the $\mathrm{P}$ gene mRNA editing sequence apparently requires bipartite replication promoters and hexamer length genomes. However, none of the above explains why the $\mathrm{NP}^{\mathrm{Q} 202 \mathrm{~A}}$ mutation is apparently so lethal that viruses harboring it have not been recovered from cDNA. It is hard to imagine how this lethality would result simply from allowing initiation of RNA synthesis in a CRII-independent manner, given how vigorously $\mathrm{NP}^{\mathrm{Q} 202 \mathrm{~A}}$ drives minigenome replication. In our present understanding of paramyxovirus RNA synthesis, all synthesis begins at the genome $3^{\prime}$ end, and each RdRp is then committed to the mutually exclusive tasks of mRNA synthesis or genome replication. This choice is thought to depend on whether leader RNA synthesis terminates and a capped mRNA is initiated at the first gene-start site, or whether leader RNA begins being assembled with NP before it terminates, and this RdRp is then locked into genome replication. Given these two very different forms of viral RNA synthesis, which presumably involve alternate $\mathrm{RdRp}$ conformations, each RdRp must remain committed to each process until that process has been completed. It is tempting to speculate that CRII plays a role in addition to that of a simple promoter element. In the absence of RdRp/CRII interaction during the initiation of $3^{\prime}$ end RNA synthesis, the ability of RdRp to subsequently adopt the conformations of committed transcriptases and 
replicases may be compromised. The Q202A mutation may thus cause the polymerase to be so error prone that infectious virus cannot be recovered.

\section{MATERIALS AND METHODS}

\section{Cells}

BSR T7/5 cells that constitutively expressed T7 RNA polymerases (Buchholz et al. 1999) were cultured in Dulbecco's modified Eagle's medium supplemented with $10 \%$ fetal calf serum.

\section{Plasmid construction}

Rluc expressing hPIV2 minigenome (hPIV2-Rluc) composed of leader, $5^{\prime}$ UTR of NP mRNA, 3'UTR of L mRNA, trailer and Rluc gene, which has been used as "normal" hPIV2 minigenome (Matsumoto et al. 2016, 2017), was represented as AG/CRII ${ }^{\text {minus }}$ in this study (hPIV2-Rluc AG/CRII ${ }^{\text {minus }}$ ), because $\mathrm{AG}^{\mathrm{CRII}}$ that is intrinsically included in the coding region of $\mathrm{L}$ had been deleted. The hPIV2-Rluc with AG ${ }^{\text {CRII }}$ (hPIV2 Rluc AG ${ }^{\mathrm{wt}}$ ) expressing plasmid was constructed by adding CRII to hPIV2-Rluc AG/CRII ${ }^{\text {minus }}$ by using a standard PCR mutagenesis method. Plasmids expressing trailer-trailer copyback-like minigenome and gene start signal deleted minigenome were constructed by modifying hPIV2-Rluc AG/CRII ${ }^{\text {minus }}$ by using a standard PCR mutagenesis method. All minigenomes were expressed as the negative sense RNA under the control of a T7 RNA polymerase promoter. hPIV2 $\mathrm{NP}^{\mathrm{wt}}$ and $\mathrm{NP}^{\mathrm{Q} 202 \mathrm{~A}}, \mathrm{P}, \mathrm{L}$ and firefly luciferase (Fluc) genes cloned into pTM1 vector, which contains a T7 promoter and an encephalomyocarditis virus internal ribosome entry site, were as described previously (Matsumoto et al. 2017).

\section{hPIV2 minireplicon assay}

The hPIV2 Rluc minireplicon assay was performed in BSR T7/5 cells cultured in 12-well plates. One-hundred thousand BSR T7/5 cells were seeded in 12-well plate. Plasmids; hPIV2-Rluc $(0.5 \mu \mathrm{g})$, pTM1-L $(0.375 \mu \mathrm{g}),-\mathrm{P}(0.2 \mu \mathrm{g})$, and -NP $(0.375 \mu \mathrm{g})$ or empty vector, and Fluc $(0.1 \mu \mathrm{g})$ were transfected by using XtremeGENE HP (Roche). At $24 \mathrm{~h}$ post-tranfection, the Rluc and Fluc activities were measured by using the Dual Luciferase Assay Kit (Promega) according to the manufacturer's instruction. All obtained results of Rluc were normalized by the expression levels of Fluc.

\section{Analysis of antigenome replication during hPIV2 Rluc minireplicon assay}

Quantification of antigenome was performed by quantitative realtime RT-PCR (qRT-PCR) using RNA sample immunoprecipitated by anti-NP mAb. At $48 \mathrm{~h}$ post-transfection, cells were lysed in lysis buffer (20 mM Tris-Cl [pH 8.0], $150 \mathrm{mM} \mathrm{NaCl}, 10 \%$ Glycerol and $1 \%$ Triton X-100) containing cOmplete Protease Inhibitor (Roche). The supernatants obtained by centrifugation were incubated with a mAb against hPIV2 NP (159-1) (Nishio et al. 1999) and protein ASepharose. The immunoprecipitated sample was subjected to RNA extraction using Isogen (Nippon Gene). To increase the efficiency of RNA extraction, Dr. GenTLE Precipitation Carrier (Takara) was used according to the manufacturer's instruction. The cDNA synthesis was carried out by the PrimeScript RT Reagent Kit (Takara) with specific primer for antigenome RNA ( $5^{\prime}$-ACCAAGGGGAAAATC AATATGTT- $3^{\prime}$ ). For trailer-trailer copyback-like antigenome, an alternative primer (5'-CATTGTTGTTATTGTTCATTTTTG- $\left.{ }^{\prime}\right)$ was used. qRT-PCR was performed by using SsoAdvanced Universal SYBR Green Supermix (Bio-Rad) using primers for Rluc gene (F: ATAACTGGTCCGCAGTGGTG, R: TAAGAAGAG GCCGCGTTACC).

\section{ACKNOWLEDGMENTS}

This work was supported by a Grant-in-Aid for Scientific Research from the Ministry of Education, Culture, Sports, Science and Technology, Japan (16K19143).

Received December 13, 2017; accepted January 18, 2018.

\section{REFERENCES}

Alayyoubi M, Leser GP, Kors CA, Lamb RA. 2015. Structure of the paramyxovirus parainfluenza virus 5 nucleoprotein-RNA complex. Proc Natl Acad Sci 112: E1792-E1799.

Albertini AAV, Wernimont AK, Muziol T, Ravelli RBG, Clapier CR, Schoehn G, Weissenhorn W, Ruigrok RWH. 2006. Crystal structure of the rabies virus nucleoprotein-RNA complex. Science 313: $360-363$.

Buchholz UJ, Finke S, Conzelmann K-K. 1999. Generation of bovine respiratory syncytial virus (BRSV) from cDNA: BRSV NS2 is not essential for virus replication in tissue culture, and the human RSV leader region acts as a functional BRSV genome promoter. $J$ Virol 73: 251-259.

Calain P, Roux L. 1993. The rule of six, a basic feature for efficient replication of Sendai virus defective interfering RNA. J Virol 67: 4822-4830.

Egelman EH, Wu SS, Amrein M, Portner A, Murti G. 1989. The Sendai virus nucleocapsid exists in at least four different helical states. J Virol 63: 2233-2243.

Green TJ, Zhang X, Wertz GW, Luo M. 2006. Structure of the vesicular stomatitis virus nucleoprotein-RNA complex. Science 313: 357-360.

Gubbay O, Curran J, Kolakofsky D. 2001. Sendai virus genome synthesis and assembly are coupled: a possible mechanism to promote viral RNA polymerase processivity. J Gen Virol 82(Pt 12): 2895-2903.

Gutsche I, Desfosses A, Effantin G, Ling WL, Haupt M, Ruigrok RWH, Sachse C, Schoehn G. 2015. Near-atomic cryo-EM structure of the helical measles virus nucleocapsid. Science 348: 704-707.

Iseni F, Baudin F, Garcin D, Marq JB, Ruigrok RWH, Kolakofsky D. 2002. Chemical modification of nucleotide bases and mRNA editing depend on hexamer or nucleoprotein phase in Sendai virus nucleocapsids. RNA 8: 1056-1067.

Kolakofsky D. 2016. Paramyxovirus RNA synthesis, mRNA editing, and genome hexamer phase: a review. Virology 498: 94-98.

Kolakofsky D, Pelet T, Garcin D, Hausmann S, Curran J, Roux L. 1998. Paramyxovirus RNA synthesis and the requirement for hexamer genome length: the rule of six revisited. J Virol 72: 891-899.

Kolakofsky D, Roux L, Garcin D, Ruigrok RWH. 2005. Paramyxovirus mRNA editing, the "rule of six" and error catastrophe: a hypothesis. $J$ Gen Virol 86(Pt 7): 1869-1877.

Liang B, Li Z, Jenni S, Rahmeh AA, Morin BM, Grant T, Grigorieff N, Harrison SC, Whelan SPJ. 2015. Structure of the L protein of vesicular stomatitis virus from electron cryomicroscopy. Cell 162: 314-327.

Luo M, Green TJ, Zhang X, Tsao J, Qiu S. 2007. Conserved characteristics of the rhabdovirus nucleoprotein. Virus Res 129: 246-251. 
Matsumoto Y, Ohta K, Goto H, Nishio M. 2016. Parainfluenza virus chimeric mini-replicons indicate a novel regulatory element in the leader promoter. J Gen Virol 97: 1520-1530.

Matsumoto Y, Ohta K, Kolakofsky D, Nishio M. 2017. A point mutation in the RNA-binding domain of human parainfluenza virus type 2 nucleoprotein elicits abnormally enhanced polymerase activity. $J$ Virol 91: e02203-e02216.

Milles S, Jensen MR, Communie G, Maurin D, Schoehn G, Ruigrok RWH, Blackledge M. 2016. Self-assembly of measles virus nucleocapsid-like particles: kinetics and RNA sequence dependence. Angew Chem Int Ed Engl 55: 9356-9360.

Murphy SK, Parks GD. 1999. RNA replication for the paramyxovirus simian virus 5 requires an internal repeated (CGNNNN) sequence motif. J Virol 73: 805-809.

Murphy SK, Ito Y, Parks GD. 1998. A functional antigenomic promoter for the paramyxovirus simian virus 5 requires proper spacing between an essential internal segment and the $3^{\prime}$ terminus. J Virol 72: 10-19.

Nishio M, Tsurudome M, Ito M, Kawano M, Kusagawa S, Komada H, Ito Y. 1999. Mapping of domains on the human parainfluenza virus type 2 nucleocapsid protein (NP) required for NP-phosphoprotein or NP-NP interaction. J Gen Virol 80(Pt 8): 2017-2022.
Pelet T, Delenda C, Gubbay O, Garcin D, Kolakofsky D. 1996. Partial characterization of a Sendai virus replication promoter and the rule of six. Virology 224: 405-414.

Reguera J, Gerlach P, Cusack S. 2016. Towards a structural understanding of RNA synthesis by negative strand RNA viral polymerases. Curr Opin Struct Biol 36: 75-84.

Ruigrok RWH, Crépin T, Kolakofsky D. 2011. Nucleoproteins and nucleocapsids of negative-strand RNA viruses. Curr Opin Microbiol 14: 504-510.

Tapparel C, Maurice D, Roux L. 1998. The activity of Sendai virus genomic and antigenomic promoters requires a second element past the leader template regions: a motif $(\mathrm{GNNNNN})_{3}$ is essential for replication. J Virol 72: 3117-3128.

Tawar RG, Duquerroy S, Vonrhein C, Varela PF, Damier-Piolle L, Castagné N, MacLellan K, Bedouelle H, Bricogne G, Bhella D, et al. 2009. Crystal structure of a nucleocapsid-like nucleoprotein-RNA complex of respiratory syncytial virus. Science 326: 1279-1283.

Walpita P. 2004. An internal element of the measles virus antigenome promoter modulates replication efficiency. Virus Res 100: 199_ 211. 

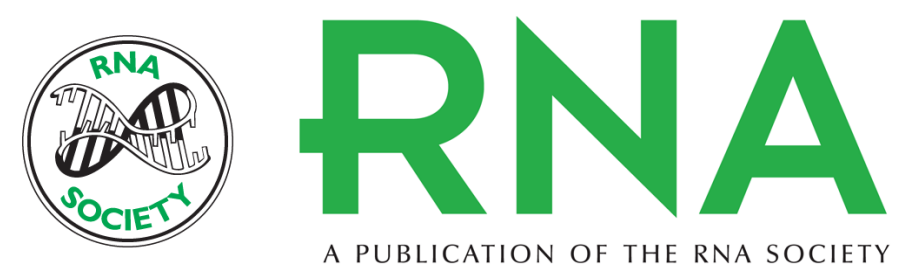

A PUBLICATION OF THE RNA SOCIETY

\section{The control of paramyxovirus genome hexamer length and mRNA editing}

Yusuke Matsumoto, Keisuke Ohta, Daniel Kolakofsky, et al.

RNA 2018 24: 461-467 originally published online January 22, 2018

Access the most recent version at doi:10.1261/rna.065243.117

\section{References This article cites 26 articles, 13 of which can be accessed free at: http://rnajournal.cshlp.org/content/24/4/461.full.html\#ref-list-1 \\ Creative This article is distributed exclusively by the RNA Society for the first 12 months after the Commons full-issue publication date (see http://rnajournal.cshlp.org/site/misc/terms.xhtml). After 12 License months, it is available under a Creative Commons License (Attribution-NonCommercial 4.0 International), as described at http://creativecommons.org/licenses/by-nc/4.0/.}

Email Alerting Receive free email alerts when new articles cite this article - sign up in the box at the Service top right corner of the article or click here.

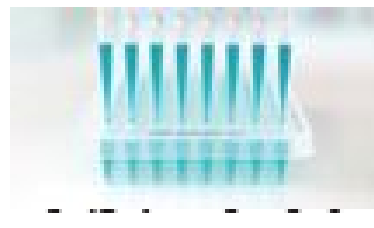

\section{Providing Precise Solutions for} your research.

To subscribe to RNA go to:

http://rnajournal.cshlp.org/subscriptions 